\title{
The Removal of Antibiotics in Sludge Drying Reed Bed
}

\author{
Chao Wang ${ }^{1,2, a}$, Yu-bo Cui ${ }^{2, b, *}$, Jun-wen Ma ${ }^{1, c}, A i-m i n ~ L i{ }^{1, d}$, Shi-fei $\mathrm{Li}^{2, \mathrm{e}}$ and \\ Shu-chang Zhang ${ }^{2, f}$
}

1 School of Environment science \& technology, Dalian University of Technology, Dalian 116024, China

2 College of Environment and Resources, Dalian Minzu University, Dalian 116600, China

${ }^{*}$ Corresponding author

a2314069082@qq.com, bcyb@dlnu.edu, c1197449439@qq.com, d384504865@qq.com, e395525756@qq.com, f903173567@qq.com

Keywords: antibiotics; sludge drying reed bed; surplus sludge

Abstract: Surplus sludge produced by sewage treatment plants is one of the important repositories of antibiotic. In order to reduce the adverse effect of the antibiotics on the environment, the sludge drying reed bed was used to treat the sludge. The experiment investigated the removal efficiency of antibiotics in the process of sludge stabilization by the dry bed with ventilation structure and the sludge drying reed bed with and without ventilation structure. The research project spent four years, including three years loading period and one year natural stabilization period. In this paper, the degradation of target antibiotics (roxithromycin, azithromycin and oxytetracycline) during the natural sludge stabilization period was studied, the effects of different conditions on the removal efficiency of antibiotic were analyzed. The results show that the sludge drying reed bed can effectively remove roxithromycin, azithromycin and oxytetracycline in the sludge, the reed and ventilation structure plays an obvious role for promoting antibiotics removal in the system.

\section{Introduction}

Since the late 1800s, antibiotics have been widely applied in the field of medical treatment [1]. After taking antibiotics, most of the antibiotics cannot be absorbed, and they will be discharged into the environment. Different kinds of antibiotics are widely detected in groundwater, surface water, drinking water and agricultural soil [2]. Antibiotics can inhibit or kill microorganisms in the environment, so that the original ecological balance is destroyed. Besides, antibiotics may also induce induced resistance genes to cause greater risks to the environment.

The removal of tetracycline and macrolide antibiotics in wastewater by activated sludge process is basically dependent on the adsorption of sludge and is rarely degraded by microorganisms, so surplus sludge produced by sewage treatment plants is an important repository of antibiotics [3, 4]. In this experiment, the sludge drying reed bed was used to stabilize antibiotics in surplus sludge. With roxithromycinz, azithromycin and oxytetracycline as targets, the high performance LC-MS/MS method was used as the detection method to investigate the antibiotic removal of the sludge drying reed bed during the natural stabilization period, so as to explore the efficiency of the removal of antibiotics in the sludge. 


\section{Materials and Methods}

Experimental Device. The sludge drying reed bed is located at the Dalian Development Zone Wastewater Treatment Plant, China. And it divided into 3 beds. The bed 1 is a traditional sludge drying bed with vent line, and the bed 2 is a sludge drying reed bed with vent line and the bed 3 is a sludge drying reed bed without vent line. The specifications of each bed are $3.0 \mathrm{~m} * 1 \mathrm{~m} * 1.3 \mathrm{~m}$, and each bed operate independently. The packing layer laid at the bottom of the three beds is the same, which is filled from bottom to top, including slag $20 \mathrm{~cm}$, gravel $20 \mathrm{~cm}$, coarse sand $5 \mathrm{~cm}$, fine sand $20 \mathrm{~cm}$. The total height of the bed packing layer is $65 \mathrm{~cm}$, and extra high is designed to reserve storage space for sludge.

Operating Conditions. The experiment lasted for 4 years, the first three years were the feeding period, and the fourth year was the natural stabilization period. The first year began in mid-may and reeds were transplanted with roots. After nearly 30 days of plant adaptation, the beds were intermittently injected into surplus sludge and the feeding sludge cycle is 7 days. The sludge volume of each bed was 450L, and the time to inject into sludge was approximately 30 minutes. Three beds were put into the surplus sludge on one side and evenly distributed on the beds after feeding sludge. The reeds in the late autumn are dry and no longer go into sludge. In the first year, second year and third year, the experimental system run 18, 24 and 23 cycles, respectively. After three years of loading, the sludge storage thickness of three beds was $18.6 \mathrm{~cm}, 12.4 \mathrm{~cm}$ and $13.7 \mathrm{~cm}$ respectively.

Collection of Sludge Samples. According to the growth of reed, sludge was sampled in April, July, September and November. Sludge layer of each bed has different sampling points based on height. The surface layer is $3 \mathrm{~cm}$ below the sludge air interface, and the bottom layer is $3 \mathrm{~cm}$ above the sediment interface. The three beds were collected the sludge in five different parallel positions on the surface and the bottom to exclude the difference of the single sludge collection, and then mix the five sludge. The surface and bottom sludge samples of bed 1 were labeled $1 \mathrm{~S}$ and $1 \mathrm{~B}$ respectively. The surface and bottom sludge samples of bed 2 were labeled $2 \mathrm{~S}$ and $2 \mathrm{~B}$ respectively. The surface and bottom sludge samples of bed 3 were labeled $3 \mathrm{~S}$ and 3B respectively. Samples were collected and transported back to the laboratory and stored at $-20^{\circ} \mathrm{C}$.

Determination of Antibiotic Concentration in Samples. The samples were vacuum freeze-dried and grinded and then screened through 100 mesh. The reference for the determination of roxithromycinz and azithromycin is GB/T20762-2006. The reference for the determination of oxytetracycline is GB/T 20762-2006. The residual concentration of antibiotics in samples was determined by LC-MS/MS.

\section{Results and Discussion}

Each sample was repeated for three times, and the average value was obtained. The average content of roxithromycinz, azithromycin and oxytetracycline in raw sludge is $95.6 \mu \mathrm{g} / \mathrm{kg}$ (dry weight), $2570 \mu \mathrm{g} / \mathrm{kg}$ (dry weight) and $4057 \mu \mathrm{g} / \mathrm{kg}$ (dry weight) respectively. The concentration of roxithromycinz and azithromycin is similar to the existing test results [5]. After three years of loading and one year of stabilization period, the change of roxithromycinz, azithromycin and oxytetracycline concentration in three beds is shown in Table 1, table 2 and table 3 respectively. The surface and bottom layer not only reflect the thickness of the sludge, but also mean the time of sludge stabilization is different. From the surface to the bottom layer, sludge stabilization time is increasing.

From table 1, table 2 and table 3, we can see that the concentration of target antibiotics shows 
obvious changes in space and time. With the prolongation of sludge stabilization time, the concentrations of antibiotics in different beds showed a significant downward trend. This shows that the increase of sludge stabilization time is of great significance for the removal of antibiotics in sludge drying reed beds.

Table 1 The residual concentration in the sample of roxithromycinz

\begin{tabular}{ccccccc}
\hline $\begin{array}{c}\text { Concentration } \\
(\mu \mathrm{g} / \mathrm{kg})\end{array}$ & $1 \mathrm{~S}$ & $1 \mathrm{~B}$ & $2 \mathrm{~S}$ & $2 \mathrm{~B}$ & $3 \mathrm{~S}$ & $3 \mathrm{~B}$ \\
\hline Apr. & 27.2 & 24.7 & 24.4 & 13.8 & 25.1 & 14.2 \\
Jul. & 25.2 & 23.1 & 22.3 & 10.7 & 23.2 & 11.5 \\
Sep. & 22.8 & 20 & 19.9 & 7.3 & 20.5 & 9.1 \\
Nov. & 20.9 & 18.4 & 17.6 & 5.9 & 18.2 & 6.9 \\
\hline
\end{tabular}

Table 2 The residual concentration in the sample of azithromycin

\begin{tabular}{ccccccc}
\hline $\begin{array}{c}\text { Concentration } \\
(\mu \mathrm{g} / \mathrm{kg})\end{array}$ & $1 \mathrm{~S}$ & $1 \mathrm{~B}$ & $2 \mathrm{~S}$ & $2 \mathrm{~B}$ & $3 \mathrm{~S}$ & $3 \mathrm{~B}$ \\
\hline Apr. & 943.4 & 804.2 & 852.4 & 489.2 & 889.8 & 539.8 \\
Jul. & 846.2 & 760.2 & 744.4 & 364 & 798.2 & 403.3 \\
Sep. & 653.3 & 523.3 & 654.1 & 203.3 & 682.7 & 238 \\
Nov. & 558.1 & 458.2 & 498.1 & 117.6 & 517.1 & 179.3 \\
\hline
\end{tabular}

Table 3 The residual concentration in the sample of oxytetracycline

\begin{tabular}{ccccccc}
\hline $\begin{array}{c}\text { Concentration } \\
(\mu \mathrm{g} / \mathrm{kg})\end{array}$ & $1 \mathrm{~S}$ & $1 \mathrm{~B}$ & $2 \mathrm{~S}$ & $2 \mathrm{~B}$ & $3 \mathrm{~S}$ & $3 \mathrm{~B}$ \\
\hline Apr. & 1316.7 & 1237.2 & 957.7 & 739.1 & 1006.4 & 809.5 \\
Jul. & 1179 & 1091.6 & 828.2 & 587.2 & 956.6 & 596.7 \\
Sep. & 997.6 & 755.2 & 653 & 328.2 & 790.1 & 394.4 \\
Nov. & 723.8 & 546 & 511 & 237.8 & 660.4 & 291.2 \\
\hline
\end{tabular}

Comparing the concentration of target antibiotics in three beds of surface sludge, it is found that the concentration of bed 2 is the lowest, followed by bed 3, and the bed 1 is the highest. The vent line can exchange the sludge layer with the air effectively and create the local aerobic condition to make the aerobic microorganisms in the sludge layer propagate quickly, so that the antibiotics in the sludge can be effectively removed. In the period of stabilization period, sludge on the surface of sludge drying reed beds will form a drying layer. Generally, the surface cracks of the sludge layer caused by plant growth will reduce the number of large cracks in the sludge layer and increase the number of small and medium cracks. Oxygen enters the sludge layer from cracks, creating local aerobic conditions, increasing the oxygen content in the surface stabilized sludge, and thus promoting the growth of aerobic microorganisms in the stabilized sludge surface layer [6]. Comparing the three beds, we found that both ventilation tube and reed have positive effects on the removal of antibiotics, and the effect of reed is bigger.

It can be seen that the reed plays an important role in the removal of antibiotics in the stabilized sludge by comparing the residual concentration of the target antibiotics in the three beds. The reed has a huge leaf crown and root, and oxygen is transported to the bottom of the sludge by the transfer of reed stem and leaf. Aerobic microorganisms grow in a low-oxygen environment around the roots of reeds, promoting the biodegradation of sludge [7]. In addition to being an oxygen-transporting 
channel, reeds can also directly absorb root exudates to promote the removal of antibiotics from the surplus sludge[8]. Reeds can release carbon sources, thus improving the root zone environment of plants, and promoting the growth and reproduction of microorganisms. At the same time, plant roots can provide growth and reproduction interface for microorganism with antibiotic degradation ability, and indirectly promote the sludge dry reed bed to remove antibiotics.

\section{Conclusions}

Sludge stabilization time is an important factor influencing the removal efficiency of antibiotics in sludge drying reed beds. With the increase of stabilization time, the removal efficiency of roxithromycinz, azithromycin and oxytetracycline is improved to some extent. Vent line and reed have positive effects on the removal of roxithromycinz, azithromycin and oxytetracycline in sludge, so the sludge drying reed bed with ventilation structure has the best effect on the removal of antibiotics.

\section{Acknowledgements}

This work was financially supported by Special projects of National Natural Science Foundation and Fundamental Research Funds for the Central University, China.

\section{References}

[1] R.R. Kumar, J.T. Lee, J.Y. Cho: Applied Biological Chemistry Vol. 55(2012), p. 701-709

[2] H.K. Tam, C.M.V.L. Wong, S.T. Yong, J. Blamey, M. González: Polar Biology Vol. 2015, 38, p. $1129-1141$

[3] B. Li, T. Zhang: Environmental Science \& Technology Vol. 44(2010), p. 3468-73.

[4] A. Göbel, C.S. Mcardell, A. Joss, H. Siegrist, W. Giger: Science of the Total Environment Vol. 372(2007), p. 361-371

[5] S. Nielsen: Water Science \& Technology A Journal of the International Association on Water Pollution Research Vol. 51(2005), p. 99-107

[6] Y.A. Hammel, R. Mohamed, E. Gremaud, M.H. Lebreton, P.A. Guy: Journal of Chromatography A Vol. 1177(2008), p. 58.

[7] Y.B. Cui, H.J. Sun, M.L. Yang, Y.H. Liu: Journal of Residuals Science \& Technology Vol. 9(2012), p. 47-53

[8] E. Yergeau, S. Sanschagrin, C. Maynard, M. Starnaud, C.W. Greer: ISME Journal: Multidisciplinary Journal of Microbial Ecology Vol. 8(2014), p. 344 